\title{
The Psychology of Sustainability and Psychological Capital: New Lenses to Examine Well-Being in the Translation Profession
}

\author{
Séverine Hubscher-Davidson ${ }^{1 *}$ \\ ${ }^{1}$ The Open University, Senior Lecturer in Translation Studies, School of Languages and Applied Linguistics, UK \\ *Corresponding Author: severine.hubscher-davidson@open.ac.uk \\ Citation: Hubscher-Davidson, S. (2020). The Psychology of Sustainability and Psychological Capital: New Lenses to Examine Well-Being in the \\ Translation Profession. European Journal of Sustainable Development Research, 4(4), em0127. https://doi.org/10.29333/ejosdr/7901 \\ ARTICLE INFO \\ Received: 28 Jan. 2020 \\ Accepted: 23 Mar. 2020

\begin{abstract}
The psychology of sustainability and sustainable development is a new research area which involves optimizing and regenerating personal resources in order to establish meaningful lives and work experiences (Di Fabio, 2017). The concept of psychological capital (PsyCap) has been linked to the psychology of sustainability due to its potential role in promoting well-being in organizations and improving people's health and performance. However, this area of sustainability science is currently absent from the translation studies literature despite its relevance for professional translators' work in today's challenging and competitive environment. In line with the argument that sustainability principles apply to a variety of disciplines, the purpose of this article is to introduce the value of the psychology of sustainability for organizational and individual well-being via key concepts of relevance to the translation profession. Within this trans-disciplinary reflection space (Di Fabio and Rosen, 2018), I will also consider the research evidence for adopting a primary prevention perspective for the benefit of professional translators. Examining translator behaviour through the lens of the psychology of sustainability is a new and
\end{abstract} \\ exciting venture that has the potential to reframe professional perspectives and translators' career paths.
}

Keywords: psychology of sustainability, sustainable development, psychological capital, translation studies

\section{INTRODUCTION}

While the Millennium Development Goals (MDGs) published in 2000 by the United Nations were ambitious and went some way towards putting people and their needs at the forefront, the Sustainable Development Goals (SDGs) developed in 2016 aimed to extend these and create a new, people-centred, aspirational, and global development agenda (Kumar, Kumar, \& Vivekadhish, 2016). In particular, the SDGs called for engagement by communities across the world, both rich and poor (Sach, 2015). A significant step change was the wider-ranging remit of the third SDG which emphasizes well-being and healthy living at all ages, and the more comprehensive nature of the eighth SDG which promotes decent work and inclusiveness, alongside economic growth.

As a result of this new focus, well-being has become a key sustainable development goal and a fundamental requirement for good health, which is defined as "a state of complete physical, mental, spiritual, and social well-being and not merely the absence of disease or infirmity" (World Health Organization, 2007). Well-being is considered an essential part of professional life and, in turn, work is considered to be central to individual well-being (e.g. Di Fabio, 2017). However, recent changes in the labour market in the European Union, such as the rise in short-term contracts and non-standard flexible forms of employment, have led to increasing job insecurity often leading to occupational stress and other psychological and physical illnesses (Chiesa et al., 2018). More specifically, it is thought that self-employed workers could be particularly affected by a competitive business environment and therefore need to pay special attention to their well-being in order to handle the challenges, uncertainty, and pressures that form part of their career trajectories (Wang et al., 2018).

Professional translators are not immune to these external pressures, and it has been acknowledged that a number of aspects of their work environment, such as time pressures, technology, and competition, are increasingly threatening these professionals. Translation can be a temporary, low-status, and poorly-paid occupation (Dam \& Zethsen, 2016), and many stressors can impact the productivity and well-being of professional translators. Professional translators have been shown to suffer from occupational stress as a result of unfair treatment from agencies, poor remuneration, and uncertainty about the future (Courtney \& Phelan, 2019). In addition, evidence suggests that the translation profession is mainly made up of part-time workers and freelancers, with the level of part-time remunerated translation activity at about $60 \%$ and the proportion of freelancers ranging from $50 \%$ to $89 \%$, depending on the country and sector (Pym et al., 2013). This points to quite an insecure and precarious profession, which some have called transitory and porous (Dam and Zethsen, 2016, p. 178). 
In this context, there have been calls in recent years to focus on translators' psychological health and well-being (BolañosMedina, 2016; Hubscher-Davidson, 2016, 2017). Atkinson (2014) argued that translators need to be able to increase what he called their 'psychological skill', i.e. a combination of self-evaluation, event evaluation, and emotional self-management. Seeing this as a key component of translators' professional success, and believing that psychological aspects of translator self-management can be taught and developed, Atkinson $(2014$, p. 8) further claimed that providing translators with the confidence they need to be able to handle the challenges they face will serve them well in professional settings. In the same vein, Hubscher-Davidson and Lehr (forthcoming) note that it is both relevant and necessary to explore the different ways that the psychological resources and resilience of budding translators can be enhanced in order to contribute to a healthy workplace climate and improve their wellbeing. Thus far, however, translation scholars have not approached the issue of translators' professional well-being through the lens of sustainable development and psychological capital, despite the fact that sustainability principles have the potential to apply to a broad range of disciplines (Di Fabio \& Rosen, 2018; Rosen, 2017).

Assuming that sustainability principles apply to the field of translation studies, the purpose of this article is to introduce the value of the psychology of sustainability for organizational and individual well-being via key concepts of relevance to the translation profession. Like in other professions, translation requires greater organizational awareness of psychologically sustainable development to facilitate the kinds of positive narratives at the personal, teamwork, and organizational level that Di Fabio (2017, p. 3) promotes. First, I will introduce the psychology of sustainability and the concept of psychological capital (PsyCap) and its components, focusing in particular on emotional intelligence (EI). Then, I will focus on how sustainability has been addressed in the translation profession so far and present some avenues for future research. Throughout I will consider the research evidence for adopting a primary prevention perspective for the benefit of professional translators. Examining translator behaviour through the lens of the psychology of sustainability is a new and exciting venture that has the potential to reframe professional perspectives and thinking around translators' career paths.

\section{THE PSYCHOLOGY OF SUSTAINABILITY AND SUSTAINABLE DEVELOPMENT}

Sustainability (avoiding the depletion of natural resources in order to maintain ecological balance) and sustainable development (development that meets the needs of the present, without compromising the ability of future generations to meet their own needs) can be viewed not only in terms of the ecological and socioeconomic environment, but also from the perspective of psychology which is concerned with "how [it] is possible to optimize the use of personal resources and the capability to regenerate them" (Chiesa et al., 2018, p. 2). Indeed, psychological processes are involved in how environmental decisions are made and in the development of behaviours that promote a culture of sustainability regarding the natural environment (Di Fabio \& Rosen, 2018). As such, adopting a psychological perspective can shed precious light on issues of sustainability.

The psychology of sustainability is a relatively new area of research and intervention, and centres around the idea that individuals' well-being is a key sustainable development goal and a fundamental requirement for good health (e.g. Di Fabio, 2017). It promotes the view that a positive work environment which promotes employee health, well-being, and performance is essential for the quality of life of every human being:

The psychology of sustainability and sustainable development is concerned with understanding how it is possible to establish meaningful lives and meaningful work experiences despite the numerous challenges, transitions, and changes that characterize the current career paths (Chiesa et al., 2018, p. 2).

In particular, occupational psychologists have noted a shift from the traditional focus on removing risks to employees' health and safety to a more recent focus on promoting growth, enrichment, creating positive experiences and narratives, building relationships, and developing a healthy work environment (Di Fabio \& Rosen, 2018 Tetrick \& Peiró, 2012; ). This new perspective places emphasis on finding innovative and positive solutions, such as regenerating resources. Leporelli and Santi (2019) highlight that this focus on optimal functioning in terms of public health is the basis for positive healthy societies. As argued by Di Fabio (2017, p. 4), challenges are viewed as opportunities, and the psychology of sustainability and sustainable development can be seen as an adaptive response to the need to develop well-being in organizations that have to cope with the challenging and unpredictable environments of the 21st century. In a sense, it could also be argued that this shift in thinking in the field of sustainability mirrors a greater focus on the psychology of success in other areas, such as the growth mindset in education contexts (e.g. Dweck, 2016) which emphasizes the idea that individuals who believe their talents can be developed (through hard work, good strategies, and input from others) will lead to more positive behaviours in the face of challenges than those who see these as fixed.

With a firm focus on the sustainability of people, and on the well-being of the person and of the environment (and also of the person within the environment), the psychology of sustainability and sustainable development attempts to facilitate the growth of both interpersonal and intrapersonal talents taking into account a wide range of environments: natural, personal, social, organizational, community, global, and cross-cultural (Di Fabio \& Rosen, 2018). As Tokarz and Malinowska (2019, p. 11) observe, the infusion of psychological assumptions into sustainability and sustainable development provides lenses for improving quality of life by focusing on key psychological aspects contributing to sustainability.

Sustainability in this framework thus also consists of actions aiming to improve people's health and well-being, known as a primary prevention perspective. For Leporelli and Santi (2019), one way to actively answer a primary preventive perspective to promote the well-being and quality of life of human beings in a sustainable environment is to design healthy cities. There are, however, other ways that a primary prevention perspective can be adopted when it comes to fostering adaptive change. 
Palazzeschi, Bucci, and Di Fabio (2018) found that it is necessary not only to develop technological innovation, but also to train individuals' capacity for so-called psychological innovation. By this, they refer to a need to increase people's personal strengths such as cognitive flexibility, resilience, acceptance of change, workplace relational civility, and enthusiasm for novelties $(2018,4)$. According to Duradoni and Di Fabio (2019), implementing dedicated training to enhance people's capability to cope with innovations and adapt to change (necessary attributes for meeting sustainable project goals and achieving growth and enrichment) could help organizations better address sustainability issues and achieve the Sustainable Development Goals introduced by the United Nations. Additionally, enhancing the resources and strengths of individuals in a primary preventive perspective could have an important impact on workers, for instance helping them to more successfully face the unpredictable and dynamic environments of current organizations (Duradoni and Di Fabio, 2019). In sum, scholars are in agreement that, to promote decent work, it is important to enhance individual resources for coping and adapting to change in professional contexts, as the sustainability of an institution largely depends on how well its members prosper (e.g. Di Fabio et al., 2018; Tur-Porcar, Cuartero-Monteagudo, \& Fernández-Garrido, 2019). This point could be particularly relevant for translators who are working inhouse within agencies or international institutions (e.g. EU, UN) where the diverse, multifaceted, and often unpredictable nature of the job requires adaptability and a willingness to continuously develop one's skills.

Primary prevention approaches aiming to build resources and strengths and to promote workers' well-being can include stress management training to enable individuals to cope with high levels of uncertainty (Chiesa et al., 2018), specific interventions seeking to foster trait emotional intelligence (Callea et al., 2019; Di Fabio \& Saklofske, 2019), or other initiatives that can enhance malleable variables of relevance to people's attitudes towards-and well-being within-their (social, natural, working) environments. As Di Fabio (2017, p. 2) notes, "primary prevention is aimed at preventing the development of a problem before it starts and, at the same time, promoting psychological well-being". The focus is thus on promoting individual, group, organizational, and inter-organizational health. Interestingly, while issues such as stress, the need to tolerate ambiguity, to regulate emotions, etc. have been acknowledged in translation studies, there are-to my knowledge-currently no published studies adopting a primary prevention approach.

The kinds of personal resources that the psychology of sustainability is concerned with, and that can be optimised and regenerated to maintain well-being, are sometimes referred to in the wider literature as psychological capital (PsyCap).

\section{PSYCHOLOGICAL CAPITAL (PsyCap)}

Individuals' psychological state has recently been viewed as a kind of 'capital' that can lead to good performance and competitive advantage (Wang et al., 2018). In addition to the traditional use of the word 'capital' in economics and finance, the term 'psychological capital' is used here to represent the value of human resources alongside other concepts such as intellectual, social, and cultural capital (Luthans et al., 2007, p. 542). As Luthans, Youssef, and Avolio (2015, p. 5-6) argue, psychological capital (PsyCap) is concerned with 'who you are' and 'who you are becoming' and, as such, is an augmentation to other capitals concerned with 'what/who you know' and 'what you have'. PsyCap interacts with other capitals to foster the optimisation of all capital resources, and is believed to represent individual motivational propensities that accrue through positive psychological constructs such as self-efficacy (Luthans et al., 2007, p. 542). It contributes to the psychology of sustainability due to its potential role in helping individuals to increase their health and well-being.

PsyCap has been shown to be relevant for career, work attitudes, job satisfaction and performance, employee engagement, organizational citizenship behaviour, and perceptions of employability (Chiesa et al., 2018; Joo, Lim, \& Kim, 2016; Kong et al., 2018; Paek et al., 2015; Soni \& Rastogi, 2019; Wang et al., 2018). In their meta-analysis of PsyCap research, Kong et al. (2018) confirmed that psychological capital is an intangible but powerful tool for affecting organizational behaviour, and that promoting the development of PsyCap should be a priority.

In the framework of positive organizational behaviour, the focus has been more specifically on psychological capacities that can be measured, developed, and managed to improve professional performance (Avey, Luthans, \& Jensen, 2009). Additionally, Luthans and his colleagues have argued that psychological constructs that can make a positive difference to work performance should be 1) grounded in theory and research, 2) have a valid measurement, 3) be open to development and change, and 4) have a positive impact on work-related individual-level performance and satisfaction (Luthans et al., 2007, p. 542). Some of the psychological constructs that have been identified to meet these criteria-and are thus considered to be components of PsyCapare hope, resilience, optimism, and self-efficacy:

[PsyCap is] an individual's positive psychological state of development and is characterized by: (1) having confidence (selfefficacy) to take on and put in the necessary effort to succeed at challenging tasks; (2) making a positive attribution (optimism) about succeeding now and in the future; (3) persevering toward goals and, when necessary, redirecting paths to goals (hope) in order to succeed; and (4) when beset by problems and adversity, sustaining and bouncing back and even beyond (resilience) to attain success (Luthans, Youssef, \& Avolio, 2007).

PsyCap has been empirically determined to be a second-order core multi-dimensional construct, with the four abovementioned components qualifying as first-order constructs (Avey et al., 2011). Nevertheless, there are other psychological resources, or positive constructs, that meet the inclusion criteria for PsyCap of being grounded in theory and research with valid measures, being state-like and open to development, and having a positive impact on attitudes, behaviours, and performance. Luthans, Youssef, and Avolio (2015, p. 30) acknowledge that there is a growing body of research on a number of positive constructs beyond the four outlined above, in particular creativity, flow, mindfulness, gratitude, forgiveness, spirituality, authenticity, 
courage, and emotional intelligence. As a dynamic capital, PsyCap therefore has the potential to evolve and to incorporate a number of relevant psychological constructs. The constructs of self-efficacy, creativity, and emotional intelligence are especially noteworthy for translation, as they have attracted much attention in the literature due to their positive impact on professional performance (e.g. Bayer-Hohenwarter, 2011; Bolaños-Medina, 2014; Hubscher-Davidson, 2016).

Interestingly, Luthans, Youssef, and Avolio (2015) did not include emotional intelligence (EI) in their original conceptualization of PsyCap, noting that the definition, measurement and validation of mixed and ability models of El were too 'shaky'. I would argue, however, that the authors did not consider the trait El construct more specifically. Trait El is defined as a constellation of emotional perceptions located at the lower levels of personality hierarchies, and thus captures how good we think we are at perceiving, regulating, and expressing emotions in order to adapt to our environment and maintain well-being (Petrides, Pita, and Kokkinaki, 2007). For instance, in their study of 157 Italian high school students, Di Fabio and Kenny (2016) found with the use of separate self-report measures (the Bar-On Emotional Intelligence Inventory and the Trait Emotional Intelligence Questionnaire) that trait El explained hedonic and eudaimonic well-being beyond the effects of personality or intelligence. Trait El theory provides an appropriate and systematic framework for the interpretation of results obtained with self-report measures of El, and the trait El construct enjoys widespread empirical support and consistently replicated findings from numerous studies that are theoretically driven, methodologically sophisticated, and independently conducted (Petrides, 2009a, 2009b, 2010, 2011). In addition the TEIQue, which is the most well-established instrument developed to operationalise trait El, has been shown to be highly reliable, to provide comprehensive coverage of the trait El sampling domain, to have good internal consistency, and to be characterised by a strong theoretical and psychometric basis (Andrei et al., 2016; Martins, Ramalho, \& Morin, 2010; Petrides et al., 2016). Finally, trait EI has been shown to be particularly beneficial in professional contexts (including translation), and trait EI training interventions have been successful in terms of improving the emotional competence of individuals for the benefit of both their health and their work performance (e.g. Di Fabio \& Kenny, 2019; Nelis et al., 2011; Schutte, Malouff, \& Thorsteinsson, 2013). One striking example is the study conducted by Nelis et al. in 2009 that examined the effectiveness of a trait El training programme consisting of four sessions of two and half hours over a 4-week period which aimed to develop the emotional skill-set of 19 university students. Results showed a significant and persistent increase in levels of trait El, and a follow-up study in 2011 showed that the training translated into real-life improvements such as work success and employability. As such, I would venture that trait El could be a key component of psychological capital that can be measured, developed, and managed to improve professional performance in the ways described by Avey, Luthans, and Jensen (2009).

\section{EMOTIONAL INTELLIGENCE AND SUSTAINABILITY}

Research on emotional intelligence has traditionally been conceptualised in two distinct ways. On the one hand, proponents of ability El define it as an intelligence which can be tested with maximum performance measures (e.g. Mayer, Salovey, \& Caruso, 2008). On the other, proponents of trait El define it as a personality trait to be tested with self-report measures (Petrides, Pita, \& Kokkinaki, 2007). The question of whether El is classed as an ability or a personality trait is a longstanding debate. As highlighted by Stough, Saklofske, and Parker (2009), publications on El illustrate a considerable diversity of opinion in relation to its measurement and uses in various applications across the workplace, health, and educational settings. Nevertheless, recent work on this complex construct has somewhat reconciled and integrated differing perspectives, and El is now thought to encompass three levels: knowledge, abilities, and traits (Kotsou et al., 2011). Because trait El is concerned with individual dispositions and the propensity to behave in a certain way in emotional situations, this is the level where PsyCap is likely to be most relevant.

PsyCap can be classified as an emotional resource (Yin et al., 2018), and trait El has been shown to promote the formation of positive strengths such as self-efficacy, hope, resilience, and optimism (Di Fabio et al., 2018; Di Fabio \& Saklofske, 2018; Gong, Chen, \& Wang, 2019). For example, people high in trait El should be more capable of managing emotions positively so as to stay optimistic and hopeful about the future. Thus, the optimisation of trait El in employees should help to improve their psychological capital, and high psychological capital leads to sustainable work behaviours, e.g. positive job performance and less job burnout (Gong, Chen, \& Wang, 2019).

The link between EI and sustainable well-being for individuals and environments has recently attracted attention in the psychological literature. Several studies have revealed the main role of El in the promotion of pro-social and pro-environmental behaviours, relatedness, well-being and sustainability (Callea et al., 2019; Ojala, 2013; Petrides et al., 2016) and trait El was found to be directly relevant to job satisfaction, job adaptability, entrepreneurial behaviour, and engagement at work (Ahmetoglu, Leutner, \& Chamorro-Premuzic, 2011; Akhtar et al., 2015; Pradhan, Jena, \& Bhattacharya, 2016). For instance, in two studies exploring the personality traits and El of 416 university students, Di Fabio and Saklofske (2019) employed four commonly used personality questionnaires, as well as The Intrapreneurial Self-Capital Scale (ISCS) and the Trait Emotional Intelligence Questionnaire Short Form (TEIQue-SF), to demonstrate that trait El explained individual intrapreneurial characteristics that are vital for the sustainable construction of one's career and life paths. These empirical results add support to the idea that El and sustainability are linked.

As it is possible that El can increase the individual and social features needed for sustainable development, acting on emotional intelligence has been mooted as a plausible intervention towards promoting sustainable behaviours (e.g. Callea et al., 2019). Di Fabio et al. $(2018,10)$ make the observation that, as El encourages a more positive state of mind, it is a fundamental competence to have so as to better face the challenges of the 21st century.

However, it is in the context of education and learning environments-rather than work-that the relationship between El and sustainable development has perhaps featured most prominently. As highlighted by Tur-Porcar, Cuartero-Monteagudo, and 
Fernández-Garrido (2019), the analysis of sustainability involves understanding improvements in people's quality of life in learning and education environments. Ojala (2013) observed that emotions are closely related to values and can thus motivate students to act in particular ways when it comes to sustainability issues. In line with this, some environmental educators encourage the teaching of psychological and emotional coping mechanisms centred around constructs such as hope and optimism as part of education for sustainable development (ESD); they suggest that this can lead to pro-environmental engagement as well as sustainable happiness, thus fostering healthy, sustainable lifestyles and communities (O'Brien, 2013, 2016; Ojala, 2013; Russell \& Oakley, 2017). For instance, although students about to graduate from translation degrees were found to have mixed feelings about issues of sustainability and a limited understanding of the environmental and well-being impact of their work, the act of actively embedding ESD within their curriculum was shown to have made a positive difference to translation students' personal and affective engagement with this topic (Hubscher-Davidson \& Panichelli-Batalla, 2016).

In the context of health and medical studies, it has been argued that higher education students face uncertain situations often involving stress or anxiety due to the nature of their work which requires specific coping strategies (Tur-Porcar, CuarteroMonteagudo, \& Fernández-Garrido, 2019). In order to overcome health risks faced by these students, El interventions are believed to be useful for empowering them and helping them to employ functional coping strategies. Like health professionals, translators and interpreters can also be subject to stressful situations, both during their training and when practicing in real-life contexts (Bontempo \& Malcolm, 2012; Korpal, 2016; Roziner \& Shlesinger, 2010). They may be asked to interpret for patients in hospitals, for criminals in courts, or they may have to translate death certificates or autopsy reports. Being able to cope with their emotions has been shown to play a crucial role in various aspects of professional translators' life and work, for instance their job satisfaction, and trait El interventions have been promoted as an effective and healthy way to prepare translators to manage their own emotions-and those of others-and to cope with the demands of their studies and work (Hubscher-Davidson, 2016, 2017; Hubscher-Davidson \& Lehr, forthcoming). It therefore makes good sense to pay special attention to translators' emotional intelligence and psychological capital, particularly during their training, as this can provide scholars with a new perspective to build a healthy and sustainable translation profession.

\section{SUSTAINABILITY IN THE TRANSLATION PROFESSION}

The issue of sustainability in the translation profession was addressed early on, for example in 2005 by Darwish who queried whether translation was a viable profession due to its status as an unregulated industry that is subject to seasonal fluctuation and is often carried out by freelancers or contractors. Lamenting the fact that translators still accept to be remunerated on a cents per word basis rather than on time, effort and expertise, as true professionals should be, Darwish (2005) asserts that this sad state of affairs is largely responsible for what he calls the mercenary nature of translation freelance work, a sense of individualism, and unrealistic performance expectations. According to Darwish (2005, p. 89), translation agencies who recruit freelancers treat them as 'worker bees and soldier ants' resulting in translators who feel alienated, devalued, and exploited. He argued that their 24 hour/7 day a week working habits was detrimental to both their health and life quality. More recent work has shown that the situation has not significantly improved for freelance translators, and there is much evidence regarding the deplorable conditions that they work in (e.g. Abdallah, 2010). In particular, it seems that there is a gap between the translators' image of themselves as experts and the way they feel clients and society at large recognise and value their expertise (Dam \& Zhethsen, 2016).

Delving deeper into the sustainability of the translation profession, in 2003 Cronin first introduced the concept of 'translation ecology' to the field of translation studies. He has since employed the term 'eco-translation' more specifically to refer to "all forms of translation thinking and practice that knowingly engage with the challenges of human-induced environmental change" (Cronin, 2017 , p. 2). Cronin argues convincingly that, as a human and social science, translation studies cannot remain immune to the ecological shift taking place in many human and social science subjects. In addition to looking at how translation figures in our relationship with food and with other species, Cronin also examines the role of translation technology in driving unsustainable professional practices and a model of endless translation growth. Bemoaning the environmental cost of high-tech tools which make use of scarce and hazardous materials and consume a lot of energy, Cronin (2017, p. 102) proposes transitioning (back) to low-tech solutions for the benefit of both the environment and translators themselves. Indeed, in enabling the production of more, faster, and cheaper (or even free) translation services, Cronin argues that digital translation practices have led to so-called 'cyborg labour' and an industry which can no longer provide sustainable and meaningful employment (2017, p. 105). Professional translators have thus been disempowered and impoverished by wasteful technology and unsustainable forms of computer use which are quickly bringing about resource exhaustion and cultural depletion. In this light, the development of PsyCap seems all the more important for moving towards the kinds of long-term, resilient, and sustainable forms of translation that Cronin aspires to. In a way, although he does not acknowledge it as such, the translation scholar is touching on issues pertaining to the psychology of sustainability and sustainable development. As Di Fabio and Rosen (2018) foresaw, contributions from a variety of disciplines-such as translation studies-can shed precious light on how we can make concrete advances on topics of importance to humanity.

\section{CONCLUSION}

In this article, I have introduced the value of the psychology of sustainability for organizational and individual well-being via key concepts that are relevant to the translation profession. Clearly, developing individuals' PsyCap is beneficial for the sustainability of all professions, not just the translation profession. It could be argued, however, that the precarious nature of 
freelance translating-which forms the bread and butter of our profession-in addition to the fast-developing technology which is dramatically changing how translation is practiced, can render the making of meaningful lives and sustainable translation work experiences particularly tricky, and the remit of a lucky few who are able to optimise their personal strengths in order to thrive and adapt. As such, acknowledging the benefits of adopting the lens of psychological sustainable development and applying a primary prevention perspective in the field of translation studies seem to be the most adaptive way to respond to the unpredictable nature of 21 st century translation-related careers.

Leporelli and Santi (2019) made the worrying observation that economic well-being in the West has grown steadily since the Second World War but that, in contrast, the degree of satisfaction and the psychophysiological well-being of individuals has not. To remedy the situation, it is vital to help people increase their personal resources so that they can manage stress, cope with uncertainty, and benefit from more rewarding relationships. Fostering PsyCap, including the different dimensions of El, can encourage "innovative solutions for a more sustainable construction of career and life path" (Di Fabio \& Saklofske, 2019, p. 12). As argued by Di Fabio et al. (2018), developing El in particular could respond to goal number eight of the seventeen UN Sustainable Development Goals (decent work and economic growth). I would also venture that it would amply address the third SDG which emphasizes well-being and healthy living. Avenues for further research in translation could therefore include more intervention studies, not only to develop general strengths and resilience, but more specifically to identify which traits and resources are most predictive of professional success in the translation profession and how best to develop these. In a bid to positively influence professional resilience and sustainability in the translation profession, and to build the psychological capital of future translators, an intervention study rooted in this special context has been designed focusing on university students in Switzerland (HubscherDavidson and Lehr, forthcoming). Building on a set of successful controlled experimental studies in the field of emotional intelligence, this 18 hour empirically-derived training intervention is testing whether developing the emotional intelligence of students enrolled on an MA Translation programme could lead to improved emotional functioning, long-term personality changes, and positive implications for important life outcomes, such as psychological well-being and graduate employability. In this way, sustainability is embedded in the learning and education environment which was shown to be highly appropriate for the implementation of a primary prevention perspective.

Future research may also investigate other ways in which the psychological capital of translators can be strengthened. For instance, studies could explore what might usefully constitute the psychological capital needed by translators and how this might differ from the psychological capital required by other 21st century professionals, such as engineers or computer programmers. Research could also identify possible facilitators and barriers to the development of PsyCap. In this way, findings could inform translator education which might incorporate training that increases specific areas of PsyCap. In addition, professional associations also have a role to play in promoting the development of their members' psychological capital in terms of selfefficacy, emotional intelligence, and resilience via both continuing professional development opportunities and explicit regulations. This type of research and proactivity can help establish a capacity for actions and decision-making around what will constitute sustainable development in the field of translation going forward. It will also help to accomplish the vision of the SDGs to build a vibrant partnership with the private sector to achieve the UN's ambitious international development agenda by 2030 (Kumar, Kumar, \& Vivekadhish, 2016).

With the lens of the psychology of sustainability and sustainable development, my aim in this article was to create a new space for psychological reflection regarding what is really sustainable for translators in their environments. I hope that this can mark a new beginning for future research in translation studies relating to what Tokarz and Malinowska (2019, p. 2) refer to as the 'crucial civilizational outcomes' that are health and well-being.

\section{REFERENCES}

Abdallah, K. (2010). Translators' agency in production networks, in T. Kinnunen and K. Koskinen (eds), Translators' Agency (pp. 1146). Tampere: Tampere University Press.

Ahmetoglu, G., Leutner, F., \& Chamorro-Premuzic, T. (2011). EQ-Nomics: Understanding the relationship between individual differences in trait emotional intelligence and entrepreneurship. Personality and Individual Differences, 51(8), $1028-1033$.

Akhtar, R., Boustani, L., Tsivrikos, D., \& Chamorro-Premuzic, T. (2015). The engageable personality: Personality and trait El as predictors of work engagement. Personality and Individual Differences, 73, 44-49.

Andrei, F., Siegling, A. B., Aloe A. M., Baldaro, B., \& Petrides, K. V. (2016). The incremental validity of the trait emotional intelligence questionnaire (TEIQue): A systematic review and meta-analysis. Journal of Personality Assessment, 98(3), 261-276.

Atkinson, D. P. (2014). Developing psychological skill for the global language industry. An exploration of approaches to translator and interpreter training. Translation Spaces, 3, 1-24.

Avey, J. B., et al. (2011). Meta-analysis of the impact of positive psychological capital on employee attitudes, behaviors, and performance. Human Resource Development Quarterly, 22(2), 127-152. https://doi.org/10.1002/hrdq.20070

Avey, J. B., Luthans, F., \& Jensen, S. M. (2009). Psychological capital: A positive resource for combating employee stress and turnover. Human Resource Management, 48(5), 677-693. https://doi.org/10.1002/hrm

Bayer-Hohenwarter, G. (2011). "Creative shifts” as a means of measuring and promoting translational creativity. Meta: Translators' Journal, 56(3), 663-692.

Bolaños-Medina, A. (2014). Self-efficacy in translation. Translation and Interpreting Studies, 9(2), 197-218. 
Bolaños-Medina, A. (2016). Translation psychology within the framework of translator studies: new research perspectives, in C. Martín de León and V. González-Ruiz (eds), From the Lab to the Classroom and Back Again (pp. 59-99). Frankfurt: Peter Lang.

Bontempo, K., \& Malcolm, K. (2012). An ounce of prevention is worth a pound of cure: educating interpreters about the risk of vicarious trauma in healthcare settings. In K. Malcolm \& L. Swabey (eds), In Our Hands: Educating Healthcare Interpreters (pp. 105-130). Washington, DC: Gallaudet University Press.

Callea, A., et al. (2019). Are more intelligent people happier? Emotional intelligence as mediator between need for relatedness, happiness and flourishing. Sustainability, 11(4), 1022. https://doi.org/10.3390/su11041022

Chiesa, R., et al. (2018). Enhancing substainability: Psychological capital, perceived employability, and job insecurity in different work contract conditions. Sustainability, 10(7), 2475. https://doi.org/10.3390/su10072475

Courtney, J., \& Phelan, M. (2019). Translators' experiences of occupational stress and job satisfaction. Translation and Interpreting, $11(1), 100-113$.

Cronin, M. (2003). Translation and Globalization. London and New York: Routledge.

Cronin, M. (2017). Eco-Translation - Translation and Ecology in the Age of the Anthropocene. London and New York: Routledge.

Dam, H. V., \& Zethsen, K. K. (2016). 'I think it is a wonderful job.' On the solidity of the translation profession. The Journal of Specialised Translation, 25, 174-187.

Darwish, A. (2005). The translation profession in Australia: viability or survivability? Translation Watch Quarterly, 1, $82-92$.

Di Fabio, A. (2017). The psychology of sustainability and sustainable development for well-being in organizations. Frontiers in Psychology, 8, 1-7. https://doi.org/10.3389/fpsyg.2017.01534

Di Fabio, A., \& Kenny, M. E. (2016). Promoting well-being: the contribution of emotional intelligence. Frontiers in Psychology, 7. https://doi.org/10.3389/fpsyg.2016.01182

Di Fabio, A., \& Kenny, M. E. (2019). Resources for enhancing employee and organizational well-being beyond personality traits: The promise of Emotional Intelligence and Positive Relational Management. Personality and Individual Differences, 151, 1-11. https://doi.org/10.1016/j.paid.2019.02.022

Di Fabio, A., et al. (2018). Personality traits and positive resources of workers for sustainable development: Is emotional intelligence a mediator for optimism and hope? Sustainability, 10(10), 3422. https://doi.org/10.3390/su10103422

Di Fabio, A., \& Rosen, M. A. (2018). Opening the black box of psychological processes in the science of sustainable development: A new frontier. European Journal of Sustainable Development Research, 2(4), 2-6. https://doi.org/10.20897/ejosdr/3933

Di Fabio, A., \& Saklofske, D. H. (2018). The contributions of personality and emotional intelligence to resiliency. Personality and Individual Differences, 123, 140-144. https://doi.org/10.1016/j.paid.2017.11.012

Di Fabio, A., \& Saklofske, D. H. (2019). The contributions of personality traits and emotional intelligence to Intrapreneurial SelfCapital: Key resources for sustainability and sustainable development. Sustainability, 11(5), 15-18. https://doi.org/10.3390/su11051240

Duradoni, M., \& Di Fabio, A. (2019). Intrapreneurial self-capital and sustainable innovative behavior within organizations. Sustainability, 11(2), 1-10. https://doi.org/10.3390/su11020322

Dweck, C. (2016). What having a "growth mindset" actually means. Harvard Business Review, 13, 213-226.

Gong, Z., Chen, Y., \& Wang, Y. (2019). The influence of emotional intelligence on job burnout and job performance: Mediating effect of psychological capital. Frontiers in Psychology, 10, 1-11. https://doi.org/10.3389/fpsyg.2019.02707

Hubscher-Davidson, S. (2016). Trait Emotional intelligence and translation. Target. International Journal of Translation Studies, 28(1), 132-157. https://doi.org/10.1075/target.28.1.06hub

Hubscher-Davidson, S. (2017). Translation and Emotion. London and New York: Routledge.

Hubscher-Davidson, S., \& Lehr, C. (forthcoming). Improving the emotional intelligence of translators through an experimental training intervention, In C. Wang \& B. Zheng (eds), Empirical Studies in Translation and Interpreting: The Post-structuralist Approach. London and New York: Routledge.

Hubscher-Davidson, S., \& Panichelli-Batalla, S. (2016). Educating for sustainability in language degrees: A tale of 2 case-studies. International Journal of Sustainability in Higher Education, 17(3), 404-416.

Joo, B. K., Lim, D. H., \& Kim, S. (2016). Enhancing work engagement: The roles of psychological capital, authentic leadership, and work empowerment. Leadership and Organization Development Journal, 37(8), 1117-1134. https://doi.org/10.1108/LODJ-012015-0005

Kong, F., et al. (2018). Psychological capital research: a meta-analysis and implications for management sustainability. Sustainability, 10(10), 3457. https://doi.org/10.3390/su10103457

Korpal, P. (2016). Interpreting as a stressful activity: Physiological measures of stress in simultaneous interpreting. Poznan Studies in Contemporary Linguistics, 52(2), 297-316. https://doi.org/10.1515/psicl-2016-0011

Kotsou, I., Nelis, D., Gregoire, J., \& Mikolajczak, M. (2011). Emotional plasticity: Conditions and effects of improving emotional competence in adulthood. Journal of Applied Psychology, 96(4), 827-839. https://doi.org/10.1037/a0023047

Kumar, S., Kumar, N., \& Vivekadhish, S. (2016). Millennium development goals (MDGS) to sustainable development goals (SDGS): Addressing unfinished agenda and strengthening sustainable development and partnership. Indian Journal of Community Medicine, 41(1). https://doi.org/10.4103/0970-0218.170955 
Leporelli, E., \& Santi, G. (2019). From psychology of sustainability to sustainability of urban spaces: Promoting a primary prevention approach for well-being in the healthy city designing. A waterfront case study in livorno. Sustainability, 11(3), 760. https://doi.org/10.3390/su11030760

Luthans, F., et al. (2007). Positive psychological capital: Measurement and relationship with performance and satisfaction. Personnel Psychology, 60(3), 541-572. https://doi.org/10.1111/j.1744-6570.2007.00083.x

Luthans, F., Youssef, C. M., \& Avolio, B. J. (2007). Psychological Capital: Developing the Human Competitive Edge. Oxford: Oxford University Press.

Luthans, F., Youssef, C. M., \& Avolio, B. J. (2015). Psychological Capital and Beyond. Oxford and New York: Oxford University Press.

Martins, A., Ramalho, N., \& Morin, E. (2010). A comprehensive meta-analysis of the relationship between emotional intelligence and health. Personality and Individual Differences, 49(6), 554-564. https://doi.org/10.1016/j.paid.2010.05.029

Mayer, J. D., Salovey, P., \& Caruso, D. R. (2008). Emotional intelligence: New ability or eclectic traits?. American Psychologist, 63(6), 503-517. https://doi.org/10.1037/0003-066X.63.6.503

Nelis, D., et al. (2011). Increasing emotional competence improves psychological and physical well-being, social relationships, and employability. Emotion, 11(2), 354-366. https://doi.org/10.1037/a0021554

Nelis, D., et al. (2009). Increasing emotional intelligence: (How) is it possible?. Personality and Individual Differences, 47(1), 36-41. https://doi.org/10.1016/j.paid.2009.01.046

O’Brien, C. (2013). Happiness and sustainability together at last! Sustainable happiness. Canadian Journal of Education, 36(4), 228256.

O'Brien, C. (2016). Education for Sustainable Happiness and Well-being. London and New York: Routledge.

Ojala, M. (2013). Emotional awareness: On the importance of including emotional aspects in Education for Sustainable Development (ESD). Journal of Education for Sustainable Development, $7(2), \quad 167-182$. https://doi.org/10.1177/0973408214526488

Paek, S., et al. (2015). Why is hospitality employees' psychological capital important? The effects of psychological capital on work engagement and employee morale. International Journal of Hospitality Management, 50, 9-26. https://doi.org/10.1016/j.ijhm.2015.07.001

Palazzeschi, L., Bucci, O., \& Di Fabio, A. (2018). Re-thinking innovation in organizations in the industry 4.0 scenario: New challenges in a primary prevention perspective. Frontiers in Psychology, 9. https://doi.org/10.3389/fpsyg.2018.00030

Petrides, K. V. (2009a). Technical Manual for the Trait Emotional Intelligence Questionnaire (TEIQue; 1st edition, 1st printing). London: London Psychometric Laboratory.

Petrides, K. V. (2009b). Psychometric properties of the Trait Emotional Intelligence Questionnaire (TEIQue), In C. Stough, D. H. Saklofske, \& J. D. A. Parker (eds), Advances in the Measurement of Emotional Intelligence, pp. 85-101. New York: Springer.

Petrides, K. V. (2010). Trait Emotional Intelligence Theory. Industrial and Organizational Psychology, 3, $136-139$. https://doi.org/10.1111/j.1754-9434.2010.01213.x

Petrides, K. V. (2011). Ability and trait emotional intelligence, In T. Chamorro-Premuzic, S. von Stumm, \& A. Furnham (eds), The Wiley-Blackwell Handbook of Individual Differences, 656-678. Chichester: Wiley Blackwell.

Petrides, K. V., Pita, R., \& Kokkinaki, F. (2007). The location of trait emotional intelligence in personality factor space. British Journal of Psychology, 98(2), 273-289. https://doi.org/10.1348/000712606X120618

Petrides, K. V., et al. (2016). Developments in trait emotional intelligence research. Emotion Review, 8(4), $335-341$. https://doi.org/10.1177/1754073916650493

Pradhan, R. K., Jena, L. K., \& Bhattacharya, P. (2016). Impact of psychological capital on organizational citizenship behavior: Moderating role of emotional intelligence. Cogent Business and Management, 3(1), 1-16. https://doi.org/10.1080/23311975.2016.1194174

Pym, A., et al. (2013). The Status of the Translation Profession in the European Union. London: Anthem Press.

Rosen, M. A. (2017). How can we achieve the UN sustainable development goals? European Journal of Sustainable Development Research, 1(2), 1-4. https://doi.org/10.20897/ejosdr.201706

Roziner, I., \& Shlesinger, M. (2010). Much ado about something remote: Stress and performance in remote interpreting. Interpreting, 12(2), 214-247.

Russell, C., \& Oakley, J. (2017). Engaging the emotional dimensions of environmental education. Canadian Journal of Environmental Education (CJEE), 21, 13-22.

Sach, J. (2015). The Age of Sustainable Development. New York: Columbia University Press.

Schutte, N., Malouff, J., \& Thorsteinsson, E. (2013). Increasing emotional intelligence through training: Current status and future directions. The International Journal of Emotional Education, 5(1), 56-72. Retrieved from http://search.proquest.com/docview/1491267200/

Soni, K., \& Rastogi, R. (2019). Psychological capital augments employee engagement. Psychological Studies, 64(4), 465-473. https://doi.org/10.1007/s12646-019-00499-x 
Stough, C., Saklofske, D. H., \& Parker, J. D. (2009). A brief analysis of 20 years of emotional intelligence: An introduction to assessing emotional intelligence: Theory, research, and applications. In C. Stough, D. H. Saklofske, \& J. D. Parker (eds), Assessing Emotional Intelligence (pp. 3-8). Boston, MA: Springer.

Tetrick, L. E., \& Peiró, J. M. (2012). Occupational safety and health. In S. W. J. Kozlowski (ed), The Oxford Handbook of Organizational Psychology (pp. 1228-1243). Oxford: Oxford University Press.

Tokarz, A., \& Malinowska, D. (2019). From psychological theoretical assumptions to new research perspectives in sustainability and sustainable development: Motivation in the workplace. Sustainability, 11(8), 2222. https://doi.org/10.3390/su11082222

Tur-Porcar, A. M., Cuartero-Monteagudo, N., \& Fernández-Garrido, J. (2019). Learning environments in health and medical studies: The mediating role of emotional intelligence. Sustainability, 11(15), 1-10. https://doi.org/10.3390/su11154011

Wang, Y., et al. (2018). Antecedent and consequences of psychological capital of entrepreneurs. Sustainability, 10(10), 3717. https://doi.org/10.3390/su10103717

World Health Organization (2007). Workers' health: global plan of action, Sixtieth World Health Assembly, 1-8. Retrieved from http://www.who.int/occupational_health/publications/global_plan/en/

Yin, H., et al. (2018). Psychological capital, emotional labor and exhaustion: Examining mediating and moderating models. Current Psychology, 37(1), 343-356. https://doi.org/10.1007/s12144-016-9518-z 